\title{
OCORRÊNCIA DE AUTOFECUNDACÃ̃O EM SUBULINA OCTONA (BRUGUIÉRE) (PULMONATA, SUBULINIDAE) SOB CONDIC̣ÕES DE LABORATÓRIO
}

\author{
Elisabeth C. de Almeida Bessa 1.2 \\ José Luiz de Barros Araújo ${ }^{1}$
}

\begin{abstract}
OCURRENCE OF SEIIF-FIRTILIZATION IN SUBULINA OCTONA (BRI GITIERE) (PIIMONATA, SIBILINIDAL) INDER L.ABOKATORIAI. CONDIIONS. Self-fertilization in Subulina octona (Bruguiére, 1789) was observed among 32 snails. Individually isolated for 154 days. Eggs were detected in 38 to 50 days old snails; total number of ovipositions per snail varied from six-nine: number of eggs per eluster. one-nine and total number of eggs per snail, 16-56 during the period of study. A period of incubation of one to 15 days and a viability of $94.8 \%$ were observed for eggs layed by these isolated snails.

KEY WORDS. Pulmonata, Subulinidac, Subulina octona, self-fertilization
\end{abstract}

Grande parte dos trabalhos realizados sobre Subulina octona (Bruguiére, 1789) refere-se a estudos conquiológicos, sinonímia e distribuição geográfica desta espécie (Fisher \& Crosse 1878; Tryon \& Pilsbry 1906; Baker 1913; Thiele 1931).

Estudos histológicos do sistema genital de $S$. octona foram realizados por LANZIERI (1966) e alguns aspectos da anatomia e comportamento desta espécie foram enfatizados por MARCUS \& MARCUS (1968), ARAÚJO) (1982), TILlier (1989) e ARAúlo \& BESSA (1993).

Já a autofecundação em caracóis da ordem Pulmonata parece ter sido assinalada pela primeira vez por OKEN (1817) em Lymnaea auricularia. Uma lista com 21 espécies de Stylommatophora, nas quais este fenômeno foi observado, foi fornecida por LARAMBERGUE (1939). Autofecundação também foi observada para espécies de Planorhidae por COLTON (1918); BRUMPT (1928, 1941); ALLEN (1935) e Paraense (1955). Autofecundlação em $S$. octona foi, pela primeira vez, mencionada por MARCUS \& MARCUS (1968).

O objetivo deste trabalho foi investigar a ocorrência de autofecundação em S. octona sob condições de laboratório, enfocando observações sobre o tempo para o aparecimento de ovos, o número total de ovos postos por indivíduo, o número de posturas por indivíduo e o número de ovos postos por postura para moluscos precocemente isolados. Observou-se ainda o período de incubação e a viabilidade de ovos postos por moluscos autofecundados.

1) Departamento de Parasitologia. Instituto de Patologia Tropical e Saúde Pública. Universidade Federal de Goiás. 74605-050 Goiânia. Goiás. Brasil.

2) Bolsista do CNPq. 


\section{MATERIAL E MÉTODOS}

Este trabalho foi desenvolvido no laboratório de Malacologia da Universidade Federal Rural do Rio de Janeiro (Itaguaí, Rio de Janeiro).

Para caracterizar a ocorrência de autofecundação em Subulina octona, utilizaram-se 48 caracóis recém eclodidos, a partir de posturas realizadas em laboratório, por 16 moluscos. Da postura de cada um destes moluscos, foram aproveitados três jovens, dos quais, dois foram mantidos isolados um a um e o terceiro jovem foi mantido em uma caixa coletiva. Desta forma, 32 caracóis foram mantidos isolados, um a um e 16 foram mantidos em grupo. Utilizou-se dois tipos de caixa de plástico, as quais foram consideradas: a) grande, medindo $14,0 \mathrm{~cm}$ de diâmetro e $11,0 \mathrm{~cm}$ de profundidade, na qual trabalhou-se com o grupo de 16 caracóis; e b) pequena, com $9,0 \mathrm{~cm}$ de diâmetro e $5,8 \mathrm{~cm}$ de profundidade, para o estudo com os 32 moluscos isolados (um a um) e também para trabalhos com ovos. As caixas continham "terra vegetal" esterilizada (a $120^{\circ} \mathrm{C}$ por uma hora) até cerca da metade de sua altura, com exceção do experimento para determinar o período de incubação, para o qual as caixas continham uma camada de terra esterelizada de aproximadamente $1,5 \mathrm{~cm}$ de espessura. Para este experimento, 96 ovos, após a postura, foram removidos com auxílio de um pincel e distribuídos em 10 caixas, sendo que nove delas continham 10 ovos cada e a décima caixa continha seis ovos. Estes ovos foram mantidos juntos, sob a terra, no fundo da caixa, simulando a postura natural. Para ohservar a ocorrência de eclosão, removia-se cuidadosamente a terra e cada jovem encontrado era retirado da caixa. Repetiu-se diariamente este processo, até a eclosão total dos caracóis.

Diariamente as caixas eram umedecidas com água, renovando-se também o alimento dos moluscos, que se constituia de alface (Lactuca sativa Linnaeus) e ração concentrada ad libitum servida em tampas plásticas para embalagens de medicamentos. Esta ração, elaborada no laboratório, constituia-se de ração para pintos de corte (Cargil Agrícola S.A.) peneirada (tendo a peneira 1,0 mm de malha) e carbonato de cálcio (B. Herzog Comércio e Indústria) na proporção de 3:1. As caixas contendo moluscos e ovos, foram cobertas com tecido de algodão escaline preso com elástico de escritório. Para manuseio dos indivíduos e dos ovos foram utilizados pinça de relojeiro e pincel número dois, respectivamente. As leituras de temperatura (máxima e mínima) e umidade relativa do ar (Incoterm Indústria de Termômetros Ltda) foram realizadas diarimente.

\section{RESULTADOS E DISCUSSÃO}

A partir de 32 jovens recém eclodidos em 01-III-1990 e mantidos isolados, um a um, e 16 mantidos agrupados, até 01-VIII-1990, tendo estes 48 jovens a mesma origem, caracterizou-se como mostra a tabela I, a ocorrência de autofecundação para Subulina octona. Tal fato foi observado por MARCUS \& MARCUS (1968) quando os mesmos, isolaram um exemplar jovem de $S$. octona e constataram a presença de ovo no caramujo isolado. O período entre o nascimento e o aparecimento de ovos, tanto para os exemplares isolados como para aqueles 
agrupados, foi de 38 a 50 dias, com temperatura variando de $23^{\circ} \mathrm{C}$ (média das mínimas) e $26^{\circ} \mathrm{C}$ (média das máximas) e umidade relativa do ar variando entre 75 a $82 \%$. Este período foi menor quando comparado aquele citado por MARCUS \& Marcus (1968), que foi de 109 dias, embora as condições experimentais não tenham sido mencionadas por estes autores. Demonstra-se na tabela II, que o número total de posturas por molusco autofecundado variou entre seis e nove e que o total de ovos postos por moluseo foi de 16 a 56 durante os 154 dias de estudo. Tais observações não são mencionadas na literatura para S. octona; entretanto, Paraense (1955), estudando a autofecundação em Australorbis glabratus, confirma para a espécie estudada, uma grande variação para o número de ovos produzidos por espécime autofecundado nos primeiros 30 dias (119 a 589 ovos).

Tabela I. Tempos máximo e mínimo para o aparecimento de ovos, com valores modais, médios, desvio padrão (D.P.) e coeficientes de variação (C.V.), para 16 exemplares de Subulina octona, mantidos agrupados e 32 mantidos isolados desde o nascimento, observados durante 154 dias sob condições de laboratório.

\begin{tabular}{lcccccc}
\hline \multirow{2}{*}{ Moluscos } & \multicolumn{5}{c}{ Tempo de aparecimento de ovos (dias) } \\
\cline { 2 - 7 } & Maior & Menor & Moda & Média & D.P. & C.V. (\%) \\
\hline Em grupo & 50 & 38 & 40 & 43,81 & 4,415 & 10,07 \\
Isolados & 50 & 38 & 42 & 43,84 & 3,273 & 7.46 \\
\hline
\end{tabular}

Tabela II. Número total de posturas, número total de ovos por moluscos e número total de ovos por postura, observados durante 154 dias, em 32 exemplares de Subulina octona, mantidos isolados desde o nascimento sob condições de laboratório. (n) Tamanho da amostra, (D.P.) desvio padrão, (C.V.) coeficiente de variação.

\begin{tabular}{lrrrrrrr}
\hline \multicolumn{1}{c}{ Parâmetros analisados } & $n$ & & Amplitude & Moda & Mèdia & D.P. & C.V. (\%) \\
\hline Número total de posturas/molusco & 32 & 9 & 6 & 7 & 7,53 & 0,761 & 10,10 \\
Número total de ovos/molusco & 32 & 56 & 16 & 45 e 52 & 43,68 & 9,163 & 20,97 \\
Número total de ovos/postura & 241 & 9 & 1 & 7 & 5,80 & 1,688 & 29,10 \\
\hline
\end{tabular}

Ainda na tabela II, observa-se que o número total de ovos por postura variou entre um e nove. Segundo MARCus \& MARCus (1968), podem ser observados exemplares de $S$. octona contendo até nove ovos, concordando com os presentes resultados.

A figura 1 mostra o período de incubação para 96 ovos obtidos, em julho e agosto de 1990, de posturas de exemplares autofecundados. Observou-se que a eclosão ocorre entre um e 15 dias. Parece não ter havido relação entre a variação da temperatura $\left(17,5\right.$ a $\left.25,0^{\circ} \mathrm{C}\right)$, durante o período de estudo, com a eclosão. Segundo MARCUS \& MARCUS (1968) a eclosão ocorre no tempo de um a dois dias, mas estes autores não relateram a quantidade de ovos e nem em que condições foram realizados seus estudos. lidade.

Dos 96 ovos foram obtidos 91 jovens, o que representa $94,8 \%$ de viahi- 

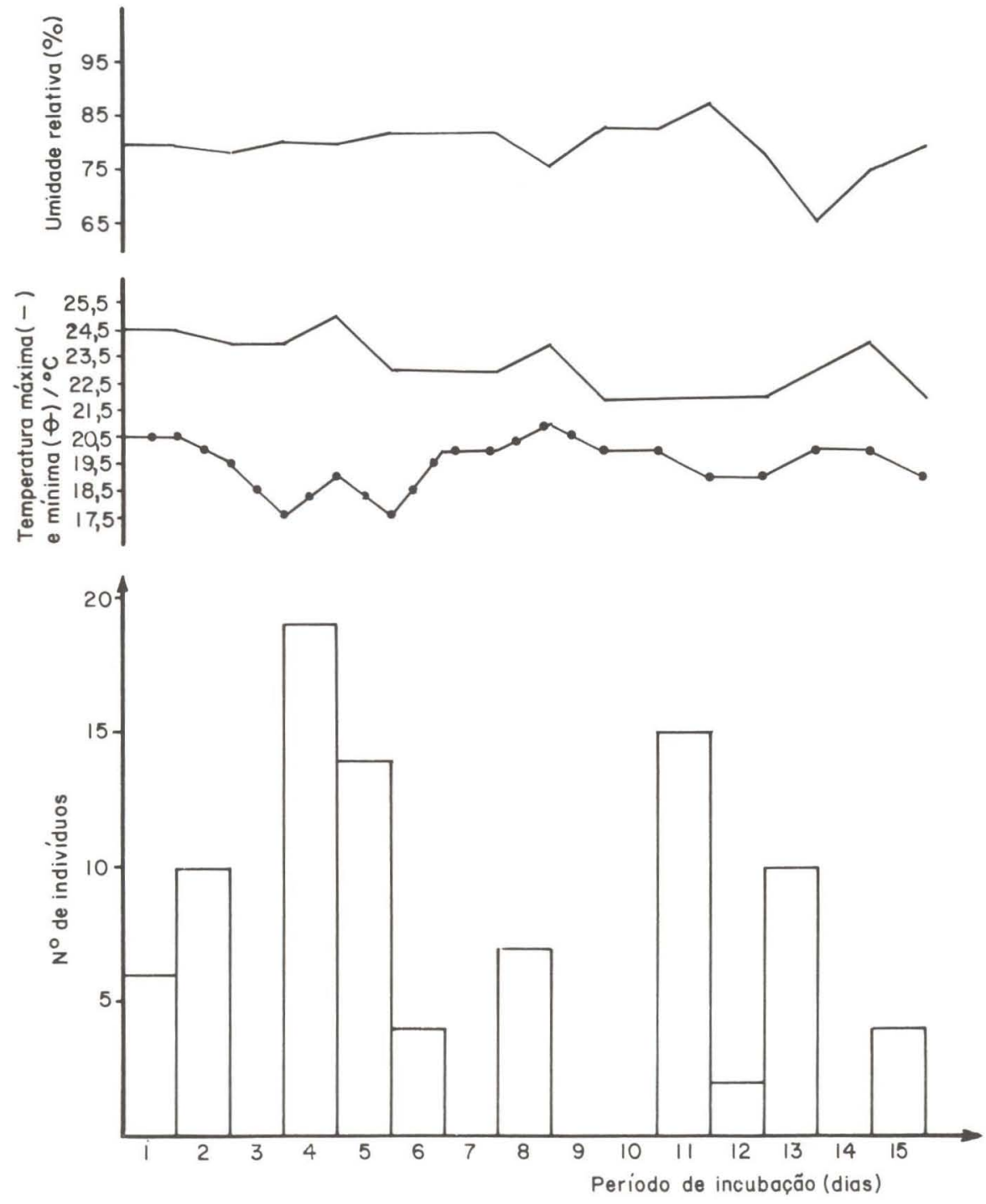

Fig. 1. Período de incubação de 96 ovos de Subulina octona, observados entre julho e agosto de 1990, provenientes de indivíduos autofecundados. 


\section{REFERÊNCIAS BIBLIOGRÁFICAS}

Allen, C. 1935. Self-fertilization. J. Conchology 20: 126.

AraúJo, J.L. DE B. 1982. Alguns moluscos terrestres como hospedeiros intermediários de parasitos de animais domésticos no Brasil: estudos sobre a anatomia, sistemática e participação em helmintoses. Tese de Doutorado, não publicada, Instituto de Biologia, Universidade Federal Rural do Rio de Janeiro, Rio de Janeiro, 103p.

AraúJo, J.L. DE B. \& E.C. DE A. Bessa. 1993. Moluscos de importância econômica no Brasil. II Subulinidae. Suhulina octoma (Bruguiére) (Molusca, Gastropoda, Pulmonata, Stylommatophora). Revta hras. Zool. 10 (3): 489-497.

BAKER, F. 1913. The land and fresh-water mollusks of the Stanford Expedition to Brazil. Proc. Acad. Nat. Sci. Philad. 65: 618-672.

BrumPT, E. 1928. Étude de l'autofécondation du mollusque aquatique pulmoné, Bullinus contortus. C.r. Acad. Sci., PAris, 168 (15): 1012-1015.

1941. Observations biologiques diverses concernant Planorhis (Australorbis) glahratus nôte intermédiaire de Schistosoma mansoni. Ann. Parasit. $18(1-3): 9-45$.

Colton, H.S. 1918. Self-fertilization in the air-breathing pond snails. Biol. Bull. 35 (1): 48-49.

FISCHER, R. \& H. CRosse. 1878. Mission scientifique an Mexique et dans l'Amérique Centrale. Recherches Zoologiques, Paris: 153-699.

LANZIERI, P.D. 1966. Alguns aspectos morfo-estruturais do aparelho genital de Subulina octona (Brugriére, 1972) (Gastropoda, Pulmonata, Subulinidae). Tese de Mestrado, não publicada. Instituto de Biologia, Universidade Federal Rural do Rio de Janeiro, Rio de Janeiro, 44p.

Larambergue, M. DE. 1939. Étude de l’autofécondation chez les gasterópedes pulmonés. Recherches sur l'aphallic et la fécondation ches Bullinus (Isidora) cantortus Michaud. Bull. Biol. 73 (1-2): 19-231.

Marcus, E. \& E. Marcus. 1968. Uher einige Subulinidae (Pulmonata) von São Paulo. Beitr. Neotrop. Fauna 5: 186-208.

OKEN, L. 1817. Schneckenjung ohne Begattung. Isis: 319.

Paraense, W.L. 1955. Autofecundação e fecundação cruzda em Australorbis glabratus. Mem. Inst. Oswaldo Cruz 53 (2,3,4): 277-291.

ThIElE, J. 1931. Hendhuch der Systematischen Weichtierunde, Berlin, Jena, $778 p$.

TILliER, S. 1989. Comparative morphology, phylogeny and classification of land snails and slugs (Gastropoda: Pulmonata: Stylommatophora). Malacologia 30 $(1-3): 1-289$.

Tryon, G.W. \& Pilsbry, H.A. 1906. Manual of Conchology, Structural and Systematic. Phyladelphia, Academy of Natural Sciences, 357p. 